\title{
Comparing comparators: a look at control arms in kidney cancer studies over the years
}

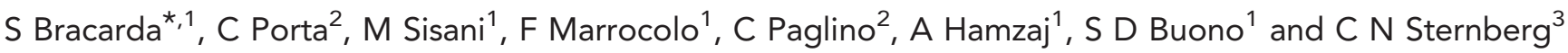 \\ ${ }^{1}$ Department of Medical Oncology, Ospedale San Donato, Istituto Toscano Tumori, Arezzo, Italy; ${ }^{2}$ Department of Medical \\ Oncology, IRCCS San Matteo University Hospital Foundation, Pavia, Italy and ${ }^{3}$ Department of Medical Oncology, Ospedale San \\ Camillo Forlanini, Rome, Italy
}

In the past decade, an increasing number of frequently positive randomised clinical trials have been completed, allowing new consideration of the present therapeutic armamentarium for advanced renal cell carcinoma. These studies were predominantly designed to compare the experimental drugs with 1 of 2 active control arms: interferon alpha-2a or sorafenib. Different from expectations, the final results of some of these studies were not in line with the predictions, and the reasons have not been fully investigated. Consequently, there is a great need for careful analysis of the studies carried out so far, chiefly the role and validity of the control arms. In this regard, the examination of patient baseline characteristics and other factors of potential interest seems fundamental for a correct analysis of the results of these trials and consequent optimal use of the available targeted agents.

Glancing at the current therapeutic approach to metastatic renal cell carcinoma (RCC), it immediately appears that we are dealing with one of the most dynamic and revolutionary events occurred in the past decade. The introduction in an 8-year lifespan of seven new and effective agents, promptly approved by the American and European regulatory authorities on account of their undeniable efficacy, has markedly reversed the therapeutic scenario of patients with advanced or metastatic disease, allowing a shift from a situation of orphan disease to a new one paradoxically characterised by a crowding of almost embarrassing opportunities (Vogelzang, 2006). Indeed, unlikely from previous therapies based on immune response modulation with cytokines, the most recent advances in molecular biology have allowed identification of a panel of new agents targeting vascular endothelial growth factor (VEGF), such as bevacizumab plus interferon (IFN), sorafenib, sunitinib, pazopanib, and axitinib, or the mammalian target of rapamycin (mTOR), such as temsirolimus and everolimus. These cell pathways are able to inhibit both angiogenesis and cell proliferation, resulting in more consistent disease control rates and prolongation of progression-free survival (PFS) (Escudier et al, 2013). Interestingly, some of the new most promising treatment options under investigation in mRCC - vaccines and antiprogrammed cell death 1 agents (checkpoint inhibitors) - are immunotherapeutic approaches, depicting a 'back to the past' treatment scenario (IMA901; Brahmer et al, 2012).

Owing to registration and commercial obligations, the initial pivotal studies with bevacizumab, sorafenib, sunitinib and pazopanib were carried out using either placebo or IFN as a comparative reference arm (Motzer et al, 2007; Escudier et al, 2007b; Sternberg et al, 2010). Once the effectiveness of these agents was established and their extended use in everyday clinical practice was completed, direct comparison with an active control arm other than placebo or IFN (the earlier 'active' arm) was strongly recommended by both physicians and regulatory authorities for better characterisation of the succeeding agents (Kane et al, 2008). In this regard, some investigators identified sorafenib as a suitable new active and already approved agent to be used as a 'comparator' (Eisen, 2012). As preclinical data showed a low affinity of this molecule for VEGF receptors and because of the available clinical data on PFS in a randomised phase 2 trial $v s$ IFN, it has been assumed that this agent could be considered the 'standard minimal reference arm,' somehow ideal for comparison with the experimental arms of new agents (Eisen, 2012). Nevertheless, nonhomogeneous and conflicting results not in line with the expectations of the original hypotheses called for deeper analyses and reappraisal of comparative studies to be carried out, particularly focusing on the role of control arms in relation to baseline patient characteristics (Eisen, 2012).

The purpose of the present investigation is to re-examine, and discuss data and clinical results in the comparative studies carried out in the treatment of RCC that included the two main represented control arms sorafenib and IFN. We perform this analysis to better understand the unexpected results sometimes observed, to evaluate the role of baseline patient population 
modifications over the years and to consider other possible baseline conditions that could positively or negatively influence the performance of evaluated agents.

\section{MATERIALS AND METHODS}

The present qualitative review of studies included data collected up to 31 March, 2013, from PubMed and the main databases of oncology and urology congresses in Europe (European Society for Medical Oncology, European Cancer Organization, European Association of Urology) and the United States (American Society of Clinical Oncology [ASCO], American Urological Association). The selection took into account only randomised phase 2 and 3 studies conducted in RCC with the following targeted agents: bevacizumab plus IFN, sorafenib, sunitinib, temsirolimus, pazopanib, everolimus, axitinib and tivozanib. Only studies having IFN or sorafenib as a control arm $v s$ an experimental arm have been included, an exception has been done for studies directly comparing IFN and sorafenib (drugs evaluated alone or in combination); these studies have been included limiting the analysis only to non-combination arm. To follow the performance of the comparator arms over time, historical data for each comparator arm were identified: these were defined as the first prospective phase 3 study or the largest meta-analysis published on PubMed able to provide PFS data for IFN or sorafenib.

Studies were divided into two groups according to first-line or second-line treatments. To describe the time trend of the comparator arms, the following parameters, if available, were analysed at baseline: accrual year range, number of enrolled patients, percentage of patients with nephrectomy, risk score according to Memorial SloanKettering Cancer Center (MSKCC) criteria and sites of metastases of potential prognostic relevance (the lung, liver, bone). The three parameters for evaluating disease control included PFS, overall survival (OS) and overall response rate (ORR).

\section{RESULTS}

After the first analysis performed on PubMed and on the main European and American congress database, 24 studies were identified as randomised studies. Of these, 14 fulfilled the selection criteria assigned in the 'Methods' section and were recognised as phase 3 in nine cases and phase 2 in five cases. A further nonrandomised study was included as a control arm for IFN. All the studies considered are reported in Table 1.

Interferon as the control arm. Five studies have been selected with IFN as a control arm: sunitinib phase 3 (Motzer et al, 2007), temsirolimus phase 3 (Hudes et al, 2007), AVOREN (Escudier et al, 2010; Escudier et al, 2013), CALGB-90206 (Rini et al, 2009), and the Phase 2 sorafenib trial conducted in 2009 (Escudier et al, 2009). The IFN historical control was drawn from a large metaanalysis that included IFN studies gathered between 1993 and 2001 (Motzer et al, 2002). Table 2 shows the results observed in the group of patients treated with IFN in six selected studies.

Nephrectomy. The percentage of patients undergoing nephrectomy increased over the years, moving from 55\% in the period 1993-2001 reported by Motzer et al (2002), to $80-90 \%$ in the subsequent years. The analysis did not include the AVOREN and temsirolimus phase 3 trials because, in the first, nephrectomy was a criteria for inclusion and, in the second, only poor-risk patients who were probably not appropriate candidates for surgery were enrolled.

Motzer score. The incidence of poor-prognosis patients according to MSKCC criteria enrolled in the selected studies decreased, from $20 \%$ of patients in the historical control to $0 \%$ in the phase 2 sorafenib trial (Escudier et al, 2009), whereas the trend of intermediate-prognosis patients remained stable $(59 \%$ in the sunitinib phase 3,64\% CALGB-90206 and 56\% observed in the AVOREN study) or decreased slightly (Escudier et al, 2009). In contrast, the trend of good-prognosis patients increased from $18 \%$ in the historical control to $51 \%$ in the sorafenib phase 2 trial by Escudier et al (2009). The analysis excluded temsirolimus phase 3 trial, as the status of 'poor-risk patients' was a mandatory inclusion criteria, although the definition of poor risk was modified during the conduct of the study and was slightly different from the standard MSKCC definition (Hudes et al, 2007).

Metastatic sites. A trend of slight increase was observed for patients with lung metastases $(67-81 \%)$ as well as for those with bone metastases (from $23 \%$ observed in historical controls to $37 \%$ in the phase 2 sorafenib study (Escudier et al, 2009)). In contrast, the percentage of patients with liver metastases at baseline appeared stable during the years.

Table 1. Legend for study indentification

\begin{tabular}{|c|c|c|}
\hline Study & Abbreviation & Study design \\
\hline \multicolumn{3}{|l|}{ IFN as control } \\
\hline $\begin{array}{l}\text { First-line setting } \\
\text { Motzer et al, } 2002 \\
\text { Motzer et al, } 2007 \\
\text { Hudes et al, } 2007 \\
\text { Escudier et al, } 2010 \\
\text { Rini et al, } 2011 \\
\text { Escudier et al, } 2009\end{array}$ & $\begin{array}{l}\text { Motzer et al, } 2002 \\
\text { Sunitinib phase } 3 \\
\text { Temsirolimus phase } 3 \\
\text { AVOREN } \\
\text { CALGB } 90206 \\
\text { Escudier et al, } 2009\end{array}$ & $\begin{array}{l}\text { IFN as comparative treatment (meta-analysis) } \\
\text { Sunitinib vs IFN (phase 3) } \\
\text { Temsirolimus vs temsirolimus + IFN vs IFN (phase 3) } \\
\text { Bevacizumab + IFN vs IFN (phase 3) } \\
\text { Bevacizumab + IFN vs IFN (phase 3) } \\
\text { Sorafenib vs IFN first line (phase 2) }\end{array}$ \\
\hline \multicolumn{3}{|l|}{ Sorafenib as control } \\
\hline $\begin{array}{l}\text { First-line setting } \\
\text { Escudier et al, } 2009 \\
\text { Jonasch et al, } 2010 \\
\text { Procopio et al, } 2011 \\
\text { Rini et al, 2012 } \\
\text { Motzer et al, } 2012 \\
\text { Hutson et al, 2013b }\end{array}$ & $\begin{array}{l}\text { Sorafenib phase } 2 \\
\text { Jonasch et al } 2010 \\
\text { ROSORC } \\
\text { AMG } 386 \\
\text { TIVO-1 } \\
\text { AGILE }\end{array}$ & $\begin{array}{l}\text { Sorafenib vs IFN (phase 2) } \\
\text { Sorafenib + IFN vs sorafenib (phase 2) } \\
\text { Sorafenib + interleukin-2 vs sorafenib (phase 2) } \\
\text { Sorafenib + AMG } 386 \text { vs AMG } 386 \text { vs sorafenib (phase 2) } \\
\text { Tivozanib vs sorafenib (phase 3) } \\
\text { Axitinib vs sorafenib (phase 3) }\end{array}$ \\
\hline $\begin{array}{l}\text { Second-line setting } \\
\text { Escudier et al, } 2010 \\
\text { Rini et al, } 2011 \\
\text { Hutson et al, 2013a }\end{array}$ & $\begin{array}{l}\text { TARGET } \\
\text { AXIS } \\
\text { INTORSECT }\end{array}$ & $\begin{array}{l}\text { Sorafenib vs placebo (phase 3) } \\
\text { Axitinib vs sorafenib (phase 3) } \\
\text { Temsirolimus vs sorafenib (phase 3) }\end{array}$ \\
\hline
\end{tabular}


Table 2. Data pertaining to IFN as control arm in six comparative studies included in the analysis

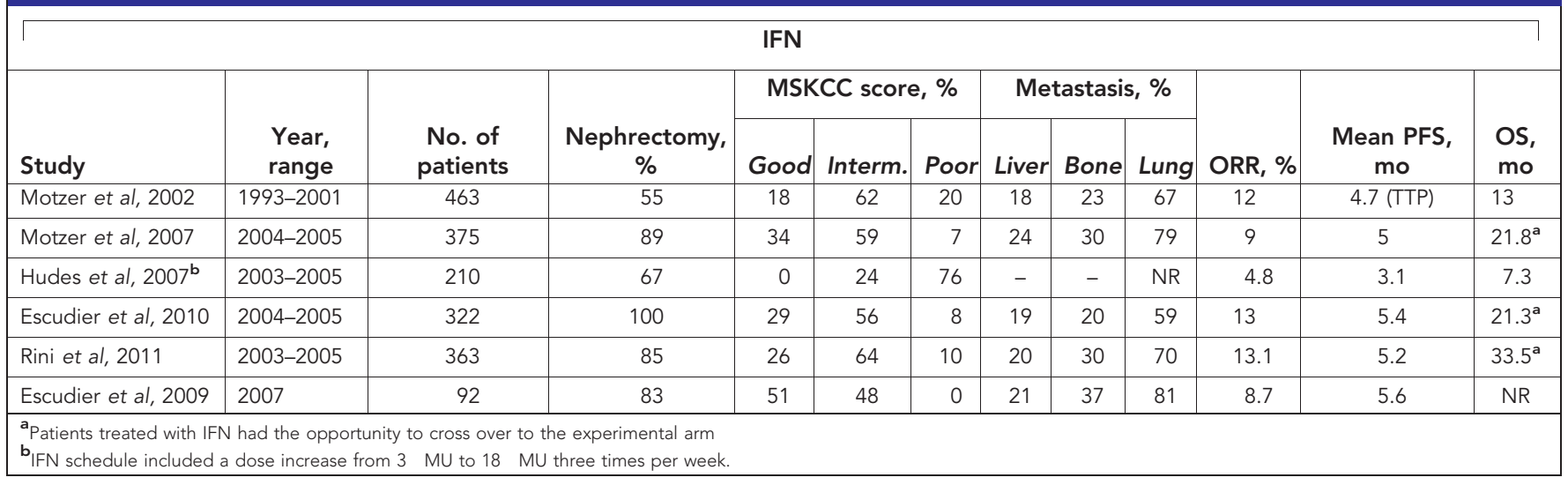

Disease control. The trend of disease control observed in the course of the years is stable in terms of ORR, slightly increased for PFS (4.7-5.6 months), as shown in Figure 1, and strongly increased for OS (from 13 months to 33.5 months). However, with the exception of the phase 2 sorafenib study (2009) (Escudier et al, 2009), in all the remaining studies PFS of the experimental arm was statistically significantly superior compared with IFN. Temsirolimus phase 3 study, which included primarily poor-risk patients, was excluded from this analysis because of the consequent reduction in benefit for all the parameters analysed.

Sorafenib as the control arm. Analysis of the databases led to the selection of seven studies designed with sorafenib as the control arm (Table 3). The group of studies concerning first-line treatment included five trials: Sorafenib + IFN vs sorafenib (conducted by Jonasch et al (2010)), ROSORC (Procopio et al, 2011), AMG 386 (Rini et al, 2012), TIVO-1 (Motzer et al, 2012) and AGILE 1051 (Hutson et al, 2013a). As TIVO-1 was undertaken in both the first and second line, this study was included in the group of first-line studies because $70 \%$ of patients were enrolled in this setting. The historical control for the first-line group was identified in the study by Escudier et al (2009).

The analysis of the second-line setting included two studies: AXIS (Rini et al, 2011) and INTORSECT (Hutson et al, 2013a) (Table 2). The historical control for the second line was the TARGET study (Escudier et al, 2007a). The three studies included populations who relapsed after cytokines (TARGET), after sunitinib (INTORSECT) and after approved VEGF inhibitors, mTOR inhibitors or cytokines (AXIS).

Nephrectomy. In these studies, the percentage of patients undergoing nephrectomy appeared stable for both the first- and secondline groups. The lowest percentage of patients with nephrectomy was observed in the ROSORC (74\%) (Procopio et al, 2011) and INTORSECT (87\%) trials (Hutson et al, 2013a).

Motzer score. In the first-line group, a high percentage (34-54\%) of good-prognosis and a low percentage $(0-6 \%)$ of poor-prognosis patients was reported, the highest percentages of patients with intermediate prognosis were observed in TIVO-1 (62\%) (Hudes et al, 2007). In the group of second-line studies, a chronological trend in the reduction of good-prognosis and an increase in intermediate- and poor-prognosis patients was documented.

Metastatic sites. A comparative analysis was possible only as far as first-line studies are analysed. Escudier et al (2009) showed the highest percentage of patients with lung metastases (87\%), whereas the lowest rate was seen in ROSORC (15\%) (Procopio et al, 2011). Except for the study by Jonasch et al (2010) and the ROSORC (13 and $5 \%$ of the cases, respectively), the percentage of patients with

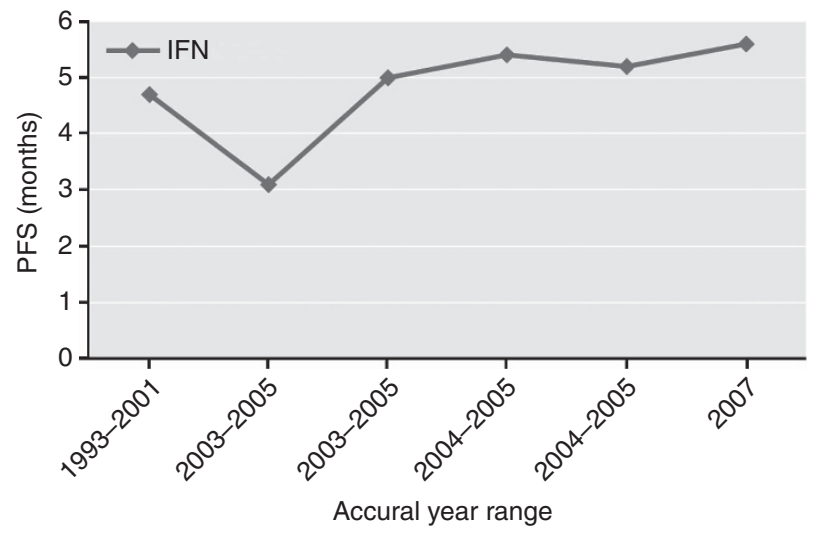

Figure 1. Trend of PFS vs year of accrual observed in the five studies including IFN as first-line treatment option.

liver metastases did not change. The highest percentage of patients with bone metastases was observed in the phase 2 sorafenib study by Escudier et al (2009) (32\%), whereas the lowest was observed in the Jonasch et al (2010) and ROSORC studies (8 and 5\%, respectively). However, it should be noted that in the ROSORC trial $52 \%$ of patients were registered as cases with 'multiple metastatic sites'.

\section{Disease control}

PFS. A general positive trend in PFS over time was observed in all the studies (Figure 2a): data rise from 5.7 months of the phase 2 study (Escudier et al, 2009) to 9.1 months of TIVO-1 (Rini et al, $2012 \mathrm{~b})$. The AGILE trial represents an exception to this trend because the median PFS falls to 6.5 months (Motzer et al, 2012). The phase 2 study (Rini et al, 2012a) was associated with the lowest PFS benefit, while the study TIVO-1 (Rini et al, 2012b) with the highest.

Figure $2 \mathrm{~b}$ shows clinical benefit in terms of PFS observed in second-line studies using sorafenib as the experimental arm. A negative trend in PFS over time is reported because data decline from 5.5 months of the TARGET study (Escudier et al, 2007a) to 4.7 months of the AXIS trial (Rini et al, 2011) and finally to the 3.9 months of the last trial INTORSECT (Hutson et al, 2013a).

Overall Survival. Similar to what was observed for the IFN group, the benefit in terms of OS observed for sorafenib showed a rising trend. In the TARGET study (Escudier et al, 2007a) the OS was 17.8 months, in AXIS (Rini et al, 2011) the OS rose to 19.3 months and in INTORSECT (Hutson et al, 2013a) the OS decreased again to 16.6 months. 
Table 3. Data pertaining to Sorafenib as control arm in nine comparative studies included in the analysis

\begin{tabular}{|c|c|c|c|c|c|c|c|c|c|c|c|c|}
\hline \multicolumn{13}{|c|}{ SORAFENIB } \\
\hline \multirow[b]{2}{*}{ Study } & \multirow[b]{2}{*}{$\begin{array}{l}\text { Year, } \\
\text { range }\end{array}$} & \multirow[b]{2}{*}{$\begin{array}{l}\text { No. of } \\
\text { patients }\end{array}$} & \multirow[b]{2}{*}{$\begin{array}{c}\text { Nephrectomy, } \\
\%\end{array}$} & \multicolumn{3}{|c|}{ MSKCC score, \% } & \multicolumn{3}{|c|}{ Metastasis, \% } & \multirow[b]{2}{*}{ ORR, \% } & \multirow[b]{2}{*}{$\begin{array}{c}\text { Mean PFS, } \\
\text { mo }\end{array}$} & \multirow[b]{2}{*}{$\begin{array}{l}\text { OS, } \\
\text { mo }\end{array}$} \\
\hline & & & & Good & Interm. & Poor & Liver & Bone & Lung & & & \\
\hline \multicolumn{13}{|l|}{ Second-line setting } \\
\hline Escudier et al, 2010 & $2003-2005$ & 351 & 94 & 52 & 48 & 0 & 26 & - & 77 & 2 & 5.5 & 17.8 \\
\hline Rini et al, 2011 & 2008-2010 & 362 & - & 28 & 36 & 33 & - & - & - & 12 & 4.7 & 19.2 \\
\hline Hutson et al, 2013a & 2009-2012 & 253 & 87 & 17 & 70 & 13 & - & - & - & 8 & 3.9 & 16.6 \\
\hline \multicolumn{13}{|l|}{ First-line setting } \\
\hline Escudier et al, 2009 & $2005-2006$ & 96 & 98 & 54 & 45 & 1 & 25 & 32 & 87 & 5 & 5.7 & - \\
\hline Jonasch et al, 2010 & 2005-2007 & 40 & 100 & 52.5 & 47.5 & 0 & 13 & 8 & 83 & 30 & 7.4 & - \\
\hline Procopio et al, 2011 & 2006-2008 & 62 & 74 & 55 & 39 & 6 & 5 & 5 & 15 & - & 7.5 & 33 \\
\hline Rini et al, 2012 & 2007-2008 & 51 & - & 37 & 61 & 2 & 27 & 18 & 71 & 26 & 9.0 & 27.1 \\
\hline Motzer et al, 2012 & 2010-2011 & 257 & 100 & 34 & 62 & 4 & 19 & 20 & 79 & 24 & 9.1 & 29.3 \\
\hline Hutson et al, 2013b & 2010-2012 & 73 & 90 & 55 & 42 & 2 & 26 & 25 & 75 & 15 & 6.5 & - \\
\hline
\end{tabular}

A Sorafenib first line

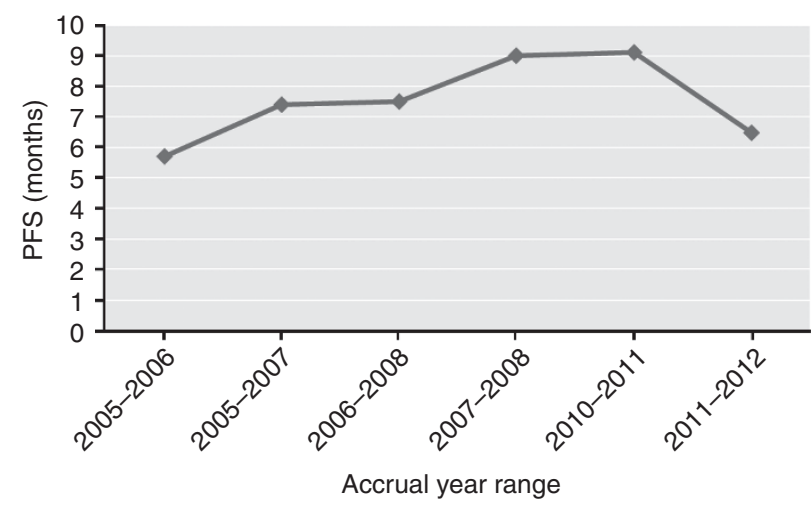

B Sorafenib second line

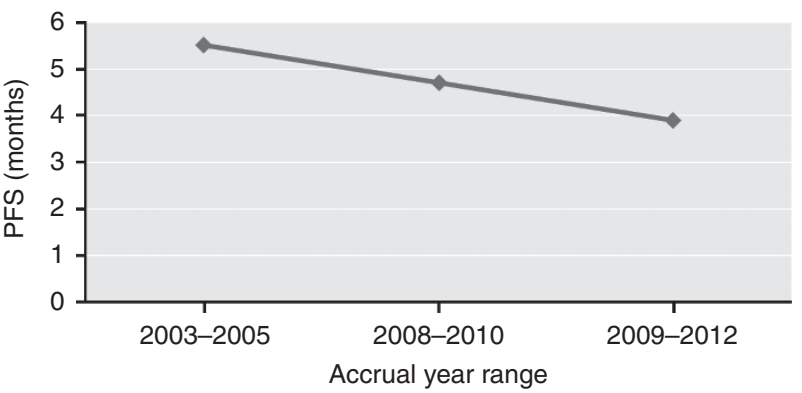

Figure 2. Trend of PFS vs year of accrual observed in the studies including sorafenib as first (A) or second (B) line treatment option.

Overall Response Rate. For the group of first-line studies, lower benefits in ORR were observed in Escudier et al (2009) and AGILE 1051; data concerning ORR benefit were constant in the remaining studies. With regard to second-line studies, the restricted benefit in terms of ORR observed in historical controls was similar to INTORSECT (Hutson et al, 2013a) and AXIS (Rini et al, 2011).

\section{DISCUSSION}

The analysis of data from the selected studies reported in Tables 2 and 3 provides information on how the features of renal cancer have evolved over the years and why some unexpected results have been observed in clinical trials.
How have the disease features evolved? The positive trend in PFS in both the IFN and sorafenib control arms observed for the firstline treatments suggests that the features of RCC patients at baseline have consistently improved over time. This finding is probably related to the improvement of baseline conditions of the patients, resulting from an increased indication for palliative nephrectomy, advances in surgical techniques and current possibilities for making the initial diagnosis much earlier than in the past (Kane et al, 2008) All of these factors resulted in improvement of the patient risk score, according to Patil (2012), however, we believe that a very important role could be also played by the improved radiological methodologies for scanning slides and the public awareness of RCC disease. The performance of IFN between 1996 and 2001 in a population with 55\% nephrectomies and $18 \%$ good-prognosis patients accounts for a benefit in terms of time to tumour progression of 4.7 months and life expectancy of 13 months (Motzer et al, 2002). Conversely, in the last study with IFN as the control arm (Escudier et al, 2009) 83\% of patients underwent nephrectomy, 51\% were good-prognosis patients and a PFS of 5.6 months was observed, confirming what Mickish and Flanigan suggested in their prospective studies about the role of palliative nephrectomy in terms of OS (Flanigan et al, 2001; Mickisch et al, 2001; Eisen, 2012). In addition, the possibility of an early diagnosis also plays an important role, allowing patients to undergo surgery in good general conditions and, consequently, improving their prognosis.

Why do unexpected results appear? In developmental studies of molecularly targeted agents, unexpected outcomes of control arms in terms of PFS and OS, disproving the statistical hypotheses, have sometimes been observed. A possible explanation of these results could derive from an indirect comparison of studies with different population. Taking this into account, careful analyses of baseline characteristics of patients in the control arm could suggest hypothesis regarding the causes of such outcomes.

Phase 2 study of first-line sorafenib $v$ s IFN. As reported, the phase 2 study comparing sorafenib $v$ IFN showed the lowest PFS associated with the use of sorafenib in first-line setting (5.6 months) (Escudier et al, 2009). We wondered how this negative result could be explained. Analysing the study, it appears that, besides an imbalance between the two experimental groups (sorafenib and IFN) at enrollment, in both treatment arms baseline patient characteristics were less favourable than in all other studies for metastatic sites and number of metastases (Escudier et al, 2012 ). Indeed, $72 \%$ of patients in the sorafenib arm and $64 \%$ in the 
IFN arm had $\geqslant 5$ metastatic sites (Szczylik and Staehler, 2007). In this situation, the performance of the IFN arm was definitely better than the IFN arms of other studies (Table 2), whereas the PFS of the sorafenib arm was the shortest compared with those observed in other first-line studies (Procopio et al, 2012). This finding should support a speculative hypothesis by Escudier et al, 2009, 2012, arguing that it is likely that in patients with a high number of metastases and highly compromising metastatic sites, the efficacy of targeted therapies and of the IFN is lower, because of the poor biology and more aggressive features of the disease.

TIVO-1. In the TIVO-1 study was reported the highest PFS for the control arm sorafenib, corresponding to 9.1 months. How could we explain this result?

With the aim to evaluate the differences between the tyrosine kinase inhibitor (TKI) tivozanib with the comparative arm sorafenib, the TIVO-1 study was conducted in a population with $70 \%$ of patients receiving first-line treatment and 30\% receiving second-line treatment after relapsing from cytokines (Motzer et al, 2012). Study results among treatment naive patients showed a PFS of 12.7 months for patients treated with tivozanib, the greatest benefit so far observed using targeted therapies in RCC. A recent document by the Oncologic Drug Advisory Committee of the US Food and Drug Administration analysing the methodology of the study (Food and Drug Oncologic Drug Advisory Comitee, 2013) questioned whether this considerable benefit is entirely the result of the drug. Looking at Table 3, it appears that the baseline characteristics of patients in TIVO-1 were similar to those of patients enrolled in AMG 386 (Rini et al, 2012): both studies show similar Motzer score profiles, with a prevalence of intermediateprognosis patients $(61 \%$ vs $62 \%)$ and about $35 \%$ good-prognosis patients (37\% vs 34\%). Similar at baseline is also the percentage of brain, bone and liver metastatic sites, whereas more favourable patient selection resulted because of nephrectomy, normally present in $80-90 \%$ of treated patients, that was a mandatory inclusion criteria in the TIVO-1, as in the AVOREN study. In fact, the nephrectomy in the TIVO-1 study was an upfront criteria because it was based on the extension of the prior phase II study (Nosov et al, 2012). These peculiarities could support a thesis that part of the benefit observed in terms of PFS could be related to the more favourable baseline conditions of the enrolled population. Confirmation should address the observation that the performance of the control arm in both TIVO-1 and AMG 386 achieved the best PFS values for sorafenib alone, exceeding 9 months (Procopio et al, 2012).

Second-line studies with sorafenib. The negative trend in PFS reported for sorafenib used in the second-line setting as control arm appear antithetical to the first-line studies, in which improvements in PFS were observed over time. A possible explanation could relate to two factors: the relevant differences in first-line treatments (cytokines and chemotherapy with TARGET, sunitinib for the other two studies) with a consequent potential negative impact on the second-line entity of PFS, as shown in the AXIS trial, and the decreasing percentage of goodprognosis baseline MSKCC scores among patients accrued in these studies (52, 28 and 13\%, respectively) with a consequent progressive increase of poor-prognosis patients $(0,33$, and $13 \%$, respectively).

Another situation that is difficult to explain is the fluctuating trend in OS of the sorafenib arm observed in these studies.

The OS trend observed in second-line therapy with sorafenib seems unusual: because of the availability of new agents and the possibility of further treatment lines, theoretically, OS should increase over time. Probably the best explanation, apart from the discussed modifications in patient study populations, is strictly connected to the percentage of patients undergoing other therapies following second-line treatment. In fact, notwithstanding the limits of the historical comparisons, we can make the following observations. In the first developmental phase 3 study, sorafenib vs placebo (TARGET), subsequent therapies in patients relapsed after sorafenib were few. When AXIS (second-line head-to-head axitinib $v s$ sorafenib) was undertaken, there was wide availability of agents for treatment following second-line therapy, and this could explain the considerable OS values observed. Looking at INTORSECT (second-line head-to-head temsirolimus vs sorafenib), the rate of patients undergoing treatment after sorafenib was only $6.3 \%$, then the consistent OS value of 16.6 months should be taken as an important sign of the effectiveness of sorafenib. In particular, the OS data observed in the INTORSECT trial were completely unexpected: the difference between sorafenib and the mTOR inhibitor exceeds 4 months of benefit. As reported by Hutson in his presentation during ESMO 2012, even though OS was a secondary end point, the magnitude of the data should not be underestimated.

AGILE 1051. As reported, the observed median PFS of 6.5 vs 10.6 months observed for sorafenib in this study clearly goes against the grain compared with previous investigations, 9.0 months in AMG 386 (Rini et al, 2012) and 9.1 months in TIVO-1 (Motzer et al, 2012). How could we explain this trend? The phase 3 first-line study AGILE evaluated the new targeted agent axitinib vs sorafenib as the control arm (Hutson et al, 2013b). In accordance with the discussant at the ASCO 2013 Genitourinary Cancers Symposium, it is likely that this weak performance of both sorafenib and axitinib may be partially justified by the particular geographical distribution of high-rate accruing centres involved in the study. Most of the centres were located in Eastern Europe, Asia, South America and Africa and likely were not yet skilled in or accustomed in the use of TKIs and possibly were forced to enter patients into clinical studies in the absence of other efficacious treatment options, mainly for economic reasons (Srinivas, 2013).

\section{CONCLUSIONS}

We deem that the present retrospective analysis of control (comparator) arm data derived from studies carried out so far in mRCC provides useful information for a more precise and rewarding use of these agents in the future.

What message has been learned from comparing comparators? Over the past decade, IFN achieved the most impressive improvement in OS, from 13 to 33.5 months, whereas sorafenib improved its mean PFS from 5.5 to a maximum of 9.1 months. Were these improvements the result of an increase in efficacy? Unquestionably not; rather, they arise from the general improvement of patient conditions at study entry, more reliable diagnostic and treatment procedures and further experience of investigators in management of adverse events. Through these new conditions, substantial improvements in the possibilities of disease control have been achieved. Considering the previous points, we believe that patients with kidney tumour can achieve additional benefits in survival through the sequential therapy of the two TKI sorafenibsunitinib or vice versa, as demonstrated in the recent phase 3 trial SWITCH (Michel, 2014). The final message to be conveyed is that, analysing the results of a study, investigators should avoid a simplistic approach that looks only at 'absolute results' in terms of PFS or OS. Instead, they must critically evaluate results in relation to the clinical conditions of patients, their prognostic risk class composition and even their geographical distribution.

\section{ACKNOWLEDGEMENTS}

Editorial assistance for this manuscript was provided by Dragonfly Editorial, funded by Bayer HealthCare. 


\section{REFERENCES}

Brahmer JR, Tykodi SS, Chow LQ, Hwu WJ, Topalian SL, Hwu P, Drake CG, Camacho LH, Kauh J, Odunsi K, Pitot HC, Hamid O, Bhatia S, Martins R, Eaton K, Chen S, Salay TM, Alaparthy S, Grosso JF, Korman AJ, Parker SM, Agrawal S, Goldberg SM, Pardoll DM, Gupta A, Wigginton JM (2012) Safety and activity of anti-PD-L1 antibody in patients with advanced cancer. N Engl J Med 366: 2455-2465.

Eisen T (2012) Discussant presentation during the oral communication in the Genitourinary (Non prostate) session Presented at the ASCO Chicago.

Escudier B, Pluzanska A, Koralewski P, Ravaud A, Bracarda S, Szczylik C, Chevreau C, Filipek M, Melichar B, Bajetta E, Gorbunova V, Bay JO, Bodrogi I, Jagiello-Gruszfeld A, Moore N (2007a) Bevacizumab plus interferon alfa-2a for treatment of metastatic renal cell carcinoma: a randomised, double-blind phase III trial. Lancet 370: 2103-2111.

Escudier B, Eisen T, Stadler WM, Szczylik C, Oudard S, Siebels M, Negrier S, Chevreau C, Solska E, Desai AA, Rolland F, Demkow T, Hutson TE, Gore M, Freeman S, Schwartz B, Shan M, Simantov R, Bukowski RM (2007b) Sorafenib in advanced clear-cell renal-cell carcinoma. N Engl J Med 356: 125-134

Escudier B, Szczylik C, Hutson TE, Demkow T, Staehler M, Rolland F, Negrier S, Laferriere N, Scheuring UJ, Cella D, Shah S, Bukowski RM (2009) Randomized phase II trial of first-line treatment with sorafenib versus interferon Alfa-2a in patients with metastatic renal cell carcinoma. J Clin Oncol 27: 1280-1289.

Escudier B, Bellmunt J, Négrier S, Bajetta E, Melichar B, Bracarda S, Ravaud A, Golding S, Jethwa S, Sneller V (2010) Phase III trial of bevacizumab plus interferon alfa-2a in patients with metastatic renal cell carcinoma (AVOREN): final analysis of overall survival. J Clin Oncol 28: 2144-2150.

Escudier B, Szczylik C, Porta C, Gore M (2012) Treatment selection in metastatic renal cell carcinoma: expert consensus. Nat Rev Clin Oncol 9: 327-337.

Escudier B, Albiges L, Sonpavde G (2013) Optimal management of metastatic renal cell carcinoma: current status. Drugs 73(5): 427-438.

Flanigan RC, Salmon SE, Blumenstein BA, Bearman SI, Roy V, McGrath PC, Caton Jr JR, Munshi N, Crawford ED (2001) Nephrectomy followed by interferon alfa- $2 \mathrm{~b}$ compared with interferon alfa- $2 \mathrm{~b}$ alone for metastatic renal cell cancer. N Engl J Med (Dec) 345: 1655-1659.

Food and Drug Oncologic Drug Advisory Comitee (2013) Food and Drug Oncologic Drug Advisory Comitee meeting of the May 2, 2013. Available at http://www.fda.gov/downloads/advisorycommittees/ committeesmeetingmaterials/drugs/oncologicdrugsadvisorycommittee/ ucm359161.pdf.

Hudes G, Carducci M, Tomczak P, Dutcher J, Figlin R, Kapoor A, Staroslawska E, Sosman J, McDermott D, Bodrogi I, Kovacevic Z, Lesovoy V, Schmidt-Wolf IG, Barbarash O, Gokmen E, O’Toole T, Lustgarten S, Moore L, Motzer RJ (2007) N Engl J Med 356: 2271-2281.

Hutson TE, Escudier B, Esteban E, Bjarnason GA, Lim HY, Pittman KB, Senico P, Niethammer A, Lu DR, Hariharan S, Motzer RJ (2013a) Randomized phase III trial of temsirolimus versus sorafenib as second-line therapy after sunitinib in patients with metastatic renal cell carcinoma. J Clin Oncol 32(8): 760-767.

Hutson TE, Lesovoy V, Al-Shukri S, Stus VP, Lipatov ON, Bair AH, Rosbrook B, Chen C, Kim S, Vogelzang NJ (2013b) Axitinib versus sorafenib as firstline therapy in patients with metastatic renal-cell carcinoma: a randomised open-label phase 3 trial. Lancet Oncol 14: 1287-1294.

IMA901 in Patients Receiving Sunitinib for Advanced/Metastatic Renal Cell Carcinoma (NCT01265901).

Jonasch E, Corn P, Pagliaro LC, Warneke CL, Johnson MM, Tamboli P, Ng C, Aparicio A, Ashe RG, Wright JJ, Tannir NM (2010) Upfront, randomized, phase 2 trial of sorafenib versus sorafenib and low-dose interferon alfa in patients with advanced renal cell carcinoma: clinical and biomarker analysis. Cancer 116: 57-65.

Kane CJ, Mallin K, Ritchey J, Cooperberg MR, Carroll PR (2008) Renal cell cancer stage migration: analysis of the National Cancer Data Base. Cancer 113: $78-83$.

Michel MS (2014) Genitourinary Cancers Symposium - January 30 - February 1, 2014 - San Francisco Marriott Marquis - San Francisco, California, USA.
Mickisch GHJ, Garin A, van Poppel H, de Prijckd L, Sylvester R (2001) Radical nephrectomy plus interferon-alfa-based immunotherapy compared with interferon alfa alone in metastatic renal-cell carcinoma: a randomised trial. Lancet 358: 966-970.

Motzer RJ, Bacik J, Murphy BA, Russo P, Mazumdar M (2002) Interferon-alfa as a comparative treatment for clinical trials of new therapies against advanced renal cell carcinoma. J Clin Oncol 20: 289-296.

Motzer RJ, Hutson TE, Tomczak P, Michaelson MD, Bukowski RM, Rixe O, Oudard S, Negrier S, Szczylik C, Kim ST, Chen I, Bycott PW, Baum CM, Figlin RA (2007) Sunitinib versus interferon alfa in metastatic renal-cell carcinoma. N Engl J Med 356(115-24): 2007.

Motzer RJ, Nosov D, Eisen T, Bondarenko I, Lesovoy V, Lipatov O, Tomczak P, Lyulko O, Tomczak P, Lyulko O, Alyasova A, Harza M, Kogan M, Alekseev BY, Sternberg CN, Szczylik C, Cella D, Ivanescu C, Krivoshik A, Strahs A, Strahs A, Esteves B, Berkenblit A, Hutson TE (2013) Tivozanib versus sorafenib as initial targeted therapy for patients with metastatic renal cell carcinoma: results from a phase III trial. J Clin Oncol 31: 3791-3799.

Nosov DA, Esteves B, Lipatov ON, Lyulko AA, Anischenko AA, Chacko RT, Doval DC, Strahs A, Slichenmyer WJ, Bhargava P (2012) Antitumor activity and safety of tivozanib (AV-951) in a phase II randomized discontinuation trial in patients with renal cell carcinoma. J Clin Oncol 30: $1678-1685$.

Patil S, Manola J, Elson P, Negrier S, Escudier B, Eisen T, Atkins M, Bukowski R, Motzer RJ (2012) Improvement in overall survival of patients with advanced renal cell carcinoma: prognostic factor trend analysis from an international data set of clinical trials. J Urol 188: 2095-2100.

Procopio G, Verzoni E, Bracarda S, Ricci S, Sacco C, Ridolfi L, Porta C, Miceli R, Zilembo N, Bajetta E (2011) Sorafenib with interleukin-2 vs sorafenib alone in metastatic renal cell carcinoma: the ROSORC trial. Br J Cancer 104: 1256-1261.

Procopio G, Verzoni E, Testa I, Nicolai N, Salvioni R, Debraud F (2012) Experience with sorafenib in the treatment of advanced renal cell carcinoma. Ther Adv Urol 4: 303-313.

Rini BI, Halabi S, Rosenberg JE, Stadler WM, Vaena DA, Ou SS, Archer L, Atkins JN, Picus J, Czaykowski P, Dutcher J, Small EJ (2009) Bevacizumab plus interferon alfa compared with interferon alfa monotherapy in patients with metastatic renal cell carcinoma: CALGB 90206. J J Clin Oncol 27: 18s (suppl; abstr LBA5019).

Rini BI, Escudier B, Tomczak P, Kaprin A, Szczylik C, Hutson TE, Michaelson MD, Gorbunova VA, Gore ME, Rusakov IG, Negrier S, Ou YC, Castellano D, Lim HY, Uemura H, Tarazi J, Cella D, Chen C, Rosbrook B, Kim S, Motzer RJ (2011) Comparative effectiveness of axitinib versus sorafenib in advanced renal cell carcinoma (AXIS): a randomised phase 3 trial. Lancet 378: 1931-1939.

Rini B, Szczylik C, Tannir NM, Koralewski P, Tomczak P, Deptala A, Dirix LY, Fishman M, Ramlau R, Ravaud A, Rogowski W, Kracht K, Sun YN, Bass MB, Puhlmann M, Escudier B (2012) AMG 386 in combination with sorafenib in patients with metastatic clear cell carcinoma of the kidney: a randomized, double-blind, placebo-controlled, phase 2 study. Cancer 118: 6152-6161.

Srinivas S (2013) Discussant presentation during the oral communication in the RCC session Presented at the ASCO genitourinary symposium Orlando, February.

Sternberg CN, Davis ID, Mardiak J, Szczylik C, Lee E, Wagstaff J, Barrios CH, Salman P, Gladkov OA, Kavina A, Zarbá JJ, Chen M, McCann L, Pandite L, Roychowdhury DF, Hawkins RE (2010) Pazopanib in locally advanced or metastatic renal cell carcinoma: results of a randomized phase III trial. J Clin Oncol 28: 1061-1068.

Szczylik CDT, Staehler M (2007) "Randomized phase II trial of first-line treatment with sorafenib versus interferon in patients with advanced renal cell carcinoma: Final results," Slide 4 (available at http://media.asco.org/ media/vm2007/10011/Lectures/4365/PPT/4.jpg. Access date 30-04-2013. ASCO meeting, Chicago.

Vogelzang NJ (2006) Treatment options in metastatic renal carcinoma: an embarrassment of riches. J Clin Oncol 24: 1-3. 